\title{
SIMULATION OF FISH MIGRATION AT DIFFERENT WATER DEPTHS BASED ON BACKPROPAGATION NEURAL NETWORK
}

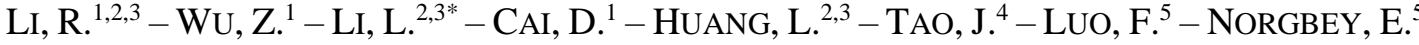 \\ ${ }^{1}$ College of Life Science and Technology, University of Guangxi, Nanning 530003, China \\ ${ }^{2}$ Guangxi Institute of Water Resources Research, Nanning 530023, China \\ ${ }^{3}$ Guangxi Key Laboratory of Water Engineering Materials and Structures, Nanning 530023, \\ China \\ ${ }^{4}$ Harbin Institute of Technology, Harbin 150080, China \\ ${ }^{5}$ College of Environment, Hohai University, Nanjing 210098, China \\ *Corresponding author \\ e-mail:LinLsky@163.com
}

(Received $26^{\text {th }}$ Sep 2018; accepted $29^{\text {th }}$ Nov 2018)

\begin{abstract}
This paper aims to disclose the law of fish migration trajectories at different water depths. For this purpose, the grass carps in a reservoir in southwestern China were taken as the targets, outdoor experiments were performed to monitor their behaviours and environmental factors in the reservoir. Then, the Hydroacoustic Technology, Inc. (HTI) acoustic tracking system and backpropagation neural network (BPNN) were introduced to simulate and analyse the migration of the fish in the natural state. Meanwhile, the vertical distribution of fish was discussed at different temperatures and dissolved oxygen contents. The results show that the BPNN algorithm has a good fitting effect on the planar migration trajectories of the fish, but fails to achieve a desirable fitting result concerning the migration trajectories in the $\mathrm{Z}$ direction. Fortunately, the fitting effect of migration trajectories was greatly enhanced by normalization. The fish were distributed differently in spring and summer across the different water depths, under the influence of water temperature and dissolved oxygen content. Overall, the fish obeyed the normal distribution in the vertical direction, and selected water depth mainly based on dissolved oxygen content. The research findings lay a scientific basis for fish resource protection, river ecology assessment and water environment restoration.
\end{abstract}

Keywords: backpropagation neural network (BPNN), migration trajectory, simulation analysis, water temperature, dissolved oxygen

\section{Introduction}

Fish are the dominant organisms in aquatic ecosystem. There exists an obvious mutual effect between fish and the water environment. On the one hand, fish are extremely sensitive to the environment of the water body; on the other hand, the water environment is directly affected by fish behaviours. It is generally agreed that ecological safety of the water body can be characterized by the diversity of fish population and variation in fish behaviours, and the fish tend to change their physiological/biochemical responses and swimming behaviours in a changing water environment. Therefore, a clear understanding of fish behaviours helps to protect the water environment and achieve quality and efficient aquaculture.

Much research has been done to reveal the effects of water environment on fish behaviours. Based on the research scope, the existing studies can be roughly divided into small-scale, medium-scale and large-scale ones. 
The small-scale research mainly investigates the physiological/biochemical responses of fish to the water environment, including blood circulation, metabolism and immunity (Santana-Garcon et al., 2014), and identifies the correlations between fish body (e.g. length and weight), meat quality and nutritional components and environmental factors like water flow, magnetic field and dissolved oxygen content. The main techniques for small-scale research include field inspections, video imaging, anatomical experiments, etc. For instance, Han et al. (2010) examined the variation in haematological parameters and digestive enzyme activity of carps at four different temperatures, and discovered the significant impact of water temperature on the metabolic status and blood components of the fish.

The medium-scale research focuses on the effects of changing water flow, water quality and magnetic field over fish behaviour. The common approach is to capture the variation in fish behaviours under changing conditions of swimming, foraging and reproduction through water through tests, video imaging, anatomical experiments, acoustic tracking and numerical simulations. For example, Wang et al. (2007) revealed the major impacts of the water habitat parameters, namely, water flow, mean water depth and river width, on the survival and reproduction of fish: the water flow affects the material/energy exchange rate and the spawning activity of fish, while the river depth and width influences the free/collective activity and thus the survival of the fish. Through onsite fish harvesting, Zhang et al. (2008) discovered that water conservancy projects lower the sediment content and turbidity, reduce the biodiversity and fish population, and bring down the dissolved oxygen content and water temperature in the downstream.

The large-scale research aims to identify the responses of fish to the changes in the water body, compare the fish migration and distribution in different habitats, and measure the health of the eco-environment in each habitat. The responses of fish range from foraging to reproduction, and the changes in the water body covers flow, depth, vorticity, temperature, sediment content and dissolved oxygen content. Popular techniques of large-scale research include acoustic tracking, model tests and $3 \mathrm{~S}$ technology (i.e. GPS (Global Positioning System), RS (Remote Sensing Technology) and GIS (geographic information system)). Below are some of the representative largescale studies. Guo et al. (2011) measured the discharge, water level, water temperature and sediment content of the Three Gorges Reservoir before and after the first filling, and concluded that the variation in these parameters delays the spawning period, reduces the spawning scale and suppresses the fertilization rate of Chinese sturgeon. Popper et al. (1998) controlled the migration behaviours of fish with underwater acoustic technique like normal sound waves and ultrasound waves, and integrated light, flow field and other factors into the technique.

The previous studies on fish migration behaviours concentrate on modelling and experiments (Haim and Portnov, 2013; Tan et al., 2004; Han et al., 2010; Zhang et al., 1987). In general, the human impacts have been emphasized over the natural impacts on fish behaviours, due to the difficulty in long-term stable monitoring of fish behaviours through existing methods of numerical analysis. Thanks to technological development, there is a shift from the traditional monitoring method (Wang et al., 2007) towards new approaches of fish behaviour monitoring, such as GPS tracking (Guo et al., 2011; Popper and Carlson, 1998), acoustic tracing (Valavanis et al., 2008; Cai and Li, 2012) and computer monitoring (Clark et al., 2004; Mouton et al., 2007). 
The traditional monitoring method investigates fish behaviours based on the life history of fish from net fishing, transport tracking to photo taking. The captured data were integrated to derive the locations of fish, and thus the general pattern of fish behaviours. The GPS tacking method originates from the popular technique of GPS positioning. Specifically, a satellite signal receiver is attached to each fish, such that the spatial position of the fish can be determined when the device receives three or more satellite signals at the same time.

The acoustic tracing method tracks fish migration based on the principle of sound propagation and signal reception. Cruz-Font et al. (2012) tacked the migration of lake trout in the US using a novel acoustic telemetry. Pepin and Miller (1993) compared the echo detection data of gill nets and catch samples, and provided new insights into the effect of habitats on fish biomass and distribution. Computer monitoring introduces the latest computer image recognition technology to the real-time monitoring of fish behaviours. However, this approach still faces difficulties and instability in operation.

The HTI acoustic tracking system combines signal reception and acoustic label positioning ( $\mathrm{Jr}$ and Matarese, 1994; Riding et al., 2009; Monk et al., 2011) into an accurate and efficient way to locate and track fish migration in all kinds of water bodies. Over the years, this system has been widely used to assess the abundance and behaviours of fish in various scenarios of the fishery industry.

Taking grass carps as the targets, this paper carries out outdoor experiments to monitor their behaviours and environmental factors in natural river habitats. Then, the HTI acoustic tracking system and backpropagation neural network (BPNN) were introduced to simulate and analyse the migration of the fish in the natural state. Meanwhile, the vertical distribution of fish was discussed at different temperatures and dissolved oxygen contents. The research findings can provide reference for the later experts to study fish behavior simulation and lay a scientific basis for fish resource protection, river ecology assessment and water environment restoration.

\section{Methodology}

\section{Equipment}

The main device of our experiments is HTI's model 291 portable acoustic tag reception system, which consists of a laptop, a model 291 portable acoustic tag receiver, a model 492 miniature acoustic tag detector, four 590-series hydrophones, forty 795 series acoustic tags, a Model 490-LP tag programmer, $400 \mathrm{~m}$ of 690-series cables, one 115 VAC power line filter, and a set of TagProgrammer/MarkTags/AcousitcTag software. The wiring diagram of the system is illustrated in Figure 1.

As shown in Figure 1, the four hydrophones are arranged on the left side: two at the bottom and two on the surface of the water body; the spacing between each pair of hydrophones is smaller than twice the listening range of a single hydrophone, such that the four hydrophones can work effectively in the hexagon in the figure. The four hydrophones are connected to the model 291 portable acoustic tag receiver. The receiver is linked to the laptop through data lines for data transmission and connected with oscilloscopes for denoising. During the monitoring, pulse signals are sent out by the acoustic tags on the fish, and received and transferred by the group of hydrophones to the tag receiver; then, the signals are denoised by the oscilloscopes before being transmitted to the laptop for storage. The user can perform real-time processing or postprocessing of these signals. 


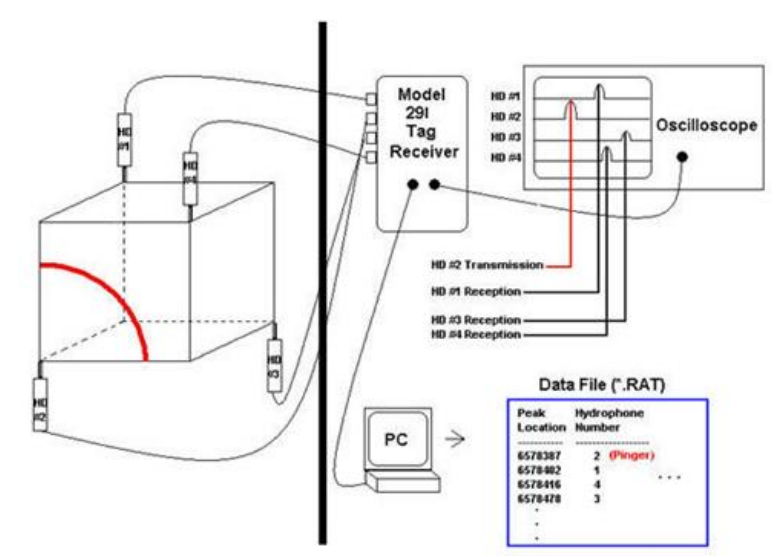

Figure 1. Wiring diagram of HTI's model 291 portable acoustic tag reception system (from HTI manual)

\section{Study area}

To study the fish migration trajectory under natural conditions, Tianbao Reservoir $\left(22^{\circ} 52^{\prime} 20^{\prime \prime} \mathrm{N}, 108^{\circ} 14^{\prime} 16^{\prime \prime} \mathrm{S}\right)$ in Nanning, China's southwestern Guangxi Autonomous Region, was selected as the study area. Located $5 \mathrm{~km}$ away from Nanning, the reservoir is the source of Keli River and a national water park. The reservoir has a water surface area of $73,000 \mathrm{~m}^{2}$, a total capacity of 13.6 million $\mathrm{m}^{3}$, and an average water depth of $6.20 \mathrm{~m}$. The dam is a homogeneous earth dam, with the crest width of $5 \mathrm{~m}$, the crest length of $132 \mathrm{~m}$ and the maximum height of $32.67 \mathrm{~m}$. The annual water supply is designed to be 2.5 million $\mathrm{m}^{3}$. The location and range of the study area are presented in Figure 2 (He et al., 2018).
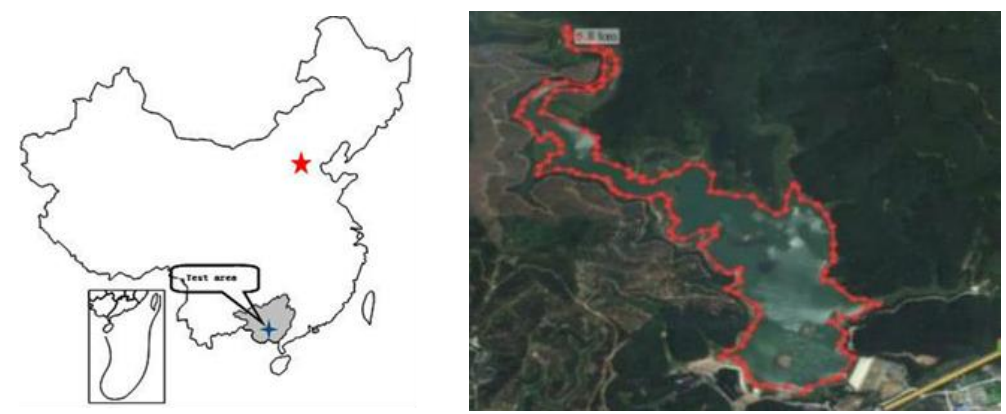

Figure 2. Location/range of the study area

\section{Target species}

There are 34 species of fish in the water system of Tianbao Reservoir, belonging to 26 genera, 9 families and 4 orders. Cypriniformes Cyprinidae are the dominant species. Specifically, Cypriniformes take up $67.65 \%$ of the total species, Perciformes account for $17.65 \%$, Siluriformes occupies $11.76 \%$, and Monopterus albus makes up $2.94 \%$. The invasive species include Tilapia nile, Tilapia mozambique, Cirrhinus mrigala, Labeo rohita, and Clarias gariepinus. From 2006 to 2007, our research group collected 34 fish samples from Tianbao reservoir, including grass carp, carp, spinibarby fish and crucian carp. Among them, the grass carp (Fig. 3) was selected our experiments. As a target 
species, grass carp is the dominant fish in the Tianbao Reservoir, and it is one of the largest species which reported production in China, over 6 million tons per year. It is also a large herbivorous freshwater fish species of the family Cyprinidae native to eastern Asia.

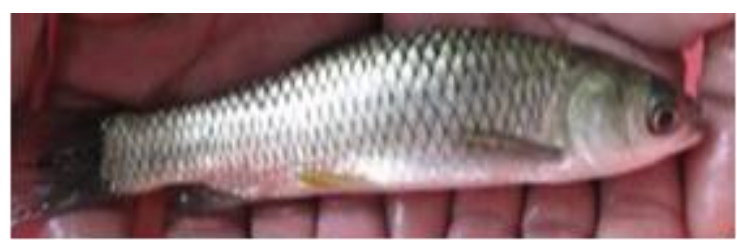

Figure 3. The target species: grass carp

\section{Field experiments}

Field experiments were carried out in April (spring) and August (summer), 2011. In each experiment, five 795-series acoustic tags (Table 1) were attached to the dorsal fin of five grass carps, denoted as Fish 01-05, respectively. As shown in Figure 4, the four hydrophones are arranged at the red, yellow, green and blue positions, respectively. The features of the hydrophone array are listed in Table 2. The tagged grass carps were released into the reservoir, and the system started to collect data at one cycle per second. Because the tagged fish need a period for adaptation, the actual sampling cycle was adjusted to $30 \mathrm{~s}$ to eliminate the interference of human activities and underwater obstacles. Meanwhile, the water temperature and dissolved oxygen content in spring and summer were also observed.

Table 1. Features of the HTI tags

\begin{tabular}{c|c|c|c|c}
\hline The tag ID & The tag type & Pulse period (msec) & Pulse delay (msec) & Fish species \\
\hline TAG-FISH01 & S & 1000 & 1 & Grass Carp \\
TAG- FISH02 & S & 1100 & 1 & Grass Carp \\
TAG- FISH03 & S & 1200 & 1 & Grass Carp \\
TAG- FISH04 & S & 1300 & 1 & Grass Carp \\
TAG- FISH05 & S & 1400 & 1 & Grass Carp \\
\hline
\end{tabular}

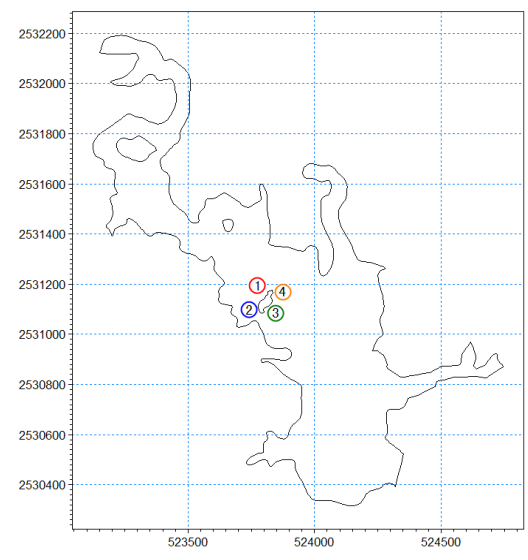

Figure 4. Layout of the hydrophone array 
Table 2. Features of the hydrophone array

\begin{tabular}{c|c|c|c|c|c|c|c}
\hline \multirow{2}{*}{ Hydrophone ID } & \multirow{2}{*}{ Type } & \multicolumn{3}{|c|}{ Coordinates } & \multirow{2}{*}{ State } & Signal gain & $\begin{array}{c}\text { Minimum monitor } \\
\text { signal }\end{array}$ \\
\cline { 3 - 5 } & & X & Y & Z & & (dB) & (Volts) \\
\hline B1 & S & 523788.69 & 2531147.64 & 87.5 & $\mathrm{R}$ & 40 & 0.1 \\
B2 & $\mathrm{S}$ & 523782.63 & 2531077.90 & 91.5 & $\mathrm{R}$ & 40 & 0.1 \\
B3 & $\mathrm{B}$ & 523833.28 & 251101.26 & 87.0 & $\mathrm{R}$ & 40 & 0.1 \\
B4 & $\mathrm{B}$ & 523830.60 & 2531151.10 & 92.0 & $\mathrm{R}$ & 40 & 0.1 \\
\hline
\end{tabular}

To disclose the law in the migration trajectories of the fish, the hydrological conditions of the reservoir were assumed to be constant. During the experiments, the water level in the reservoir basically stabilized at about $96.45 \mathrm{~m}$ (Yellow Sea Height Datum). The monitoring results on migration trajectories are shown in Figure 5.

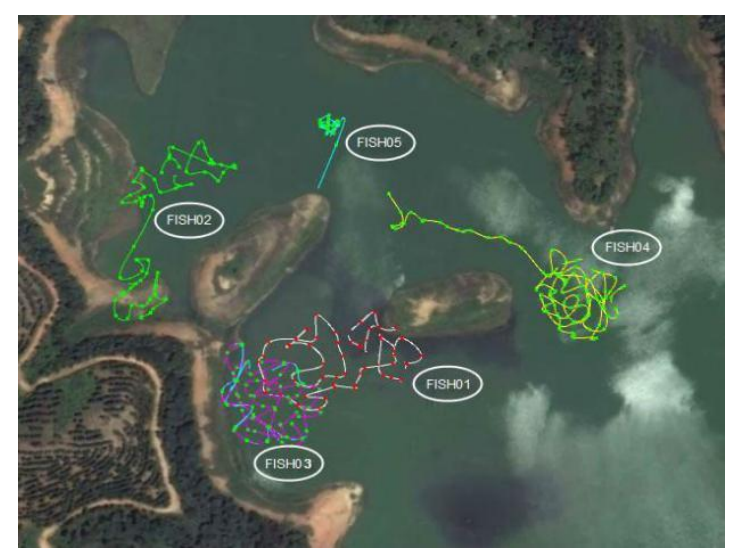

Figure 5. Monitoring results on the migration trajectories of Fish 01-05

\section{BPNN processing}

\section{BPNN algorithm}

Initialize each weight $\mathrm{w}_{\mathrm{ji}}(0)$ or threshold $\theta_{\mathrm{j}}(0)$ as a small random value.

Set the training samples: input vectors $X_{k}, k=1,2, \ldots, P$; expected outputs: $d_{k}, k=1$, $2, \ldots, P$. Perform 3-5 iterations for each input sample as follows.

Calculate the actual network output and the state of hidden layer neurons (Eq. 1):

$$
O_{k j}=f_{j}\left(\sum w_{j i} o_{k i}+\theta_{j}\right)
$$

Calculate the training error (Eqs. 2-3):

$$
\begin{aligned}
& \delta_{k j}=o_{k j}\left(1-o_{k j}\right)\left(t_{k j}-o_{k j}\right) \text { (Output layer) } \\
& \delta_{k j}=o_{k j}\left(1-o_{k j}\right) \sum_{m} \delta_{k m} w_{m j} \text { (Output layer) }
\end{aligned}
$$


Find the threshold of modified weights (Eqs. 4-5):

$$
\begin{gathered}
w_{j i}(t+1)=w_{j i}(t)+\eta \delta_{j} o_{k i}+\alpha\left\lfloor w_{j i}(t)-w_{j i}(t-1)\right\rfloor \\
\theta_{j}(t+1)=\theta_{j}(t)+\eta \delta_{j}+\alpha\left\lfloor\theta_{j}(t)-\theta_{j}(t-1)\right\rfloor
\end{gathered}
$$

If $k$ falls in $1-$ p, determine if the index meets the accuracy requirement $(E q .6)$ :

$$
E \leq \varepsilon
$$

where $\varepsilon$ is the required accuracy.

The BPNN (Hecht-Nielsen, 1988; Macbeth C et al., 1997) has only one hidden layer. The neurons in the input, hidden and output layers can configure themselves.

\section{Normalization}

When all samples have positive inputs, the weights of the hidden layer neurons can either increase or decrease at the same time, which slows down the learning speed. To speed up the convergence, it is necessary to normalize the basic unit of measurement before modelling or statistical calculation. The BPNN is trained (probability calculation) and predicted by the statistical probability of samples in events, and normalization is the statistical probability distribution unified between 0 and 1 . Through normalization, the mean input of all samples is close to zero or smaller than its mean square error.

\section{Results analysis}

\section{BPNN-based simulation of migration trajectories}

In our research, the migration trajectories of Fish 01-05 were simulated (Eqs. 1-6). The training parameters are given in Table 3. The data on the migration trajectories along the $\mathrm{X}, \mathrm{Y}$ and $\mathrm{Z}$ directions were normalized, and the values were measured before and after the normalization. The correlation coefficients between the measured values and the fitted values (Table 4) before and after the normalization were obtained through simulation and calculation. The measured data and fitted data were normalized and plotted into 3D images from the perspectives of $(45,45)$ and $(-45,-45)$ (Figs. 6-10). In these images, the blue circle lines stand for the measured data, while the red square lines represent the fitted data.

Table 3. Training parameters

\begin{tabular}{c|c|c|c|c}
\hline Number & Number of training sessions & Input layer & Hidden layer & Output layer \\
\hline FISH01 & 136000 & 1 & 7 & 3 \\
FISH02 & 132000 & 1 & 7 & 3 \\
FISH03 & 206000 & 1 & 7 & 3 \\
FISH04 & 136000 & 1 & 7 & 3 \\
FISH05 & 136000 & 1 & 7 & 3 \\
\hline
\end{tabular}


Table 4. Correlation coefficient between measured and fitted values before and after normalization

\begin{tabular}{c|c|c|c|c|c|c|c|c|c}
\hline \multirow{2}{*}{ Number } & \multicolumn{3}{|c|}{ X } & \multicolumn{3}{c|}{ Y } & \multicolumn{3}{c}{ Z } \\
\cline { 2 - 10 } & $\begin{array}{c}\text { Before } \\
\text { processing }\end{array}$ & $\begin{array}{c}\text { After } \\
\text { processing }\end{array}$ & $\begin{array}{c}\text { Increase } \\
(\%)\end{array}$ & $\begin{array}{c}\text { Before } \\
\text { processing }\end{array}$ & $\begin{array}{c}\text { After } \\
\text { processing }\end{array}$ & $\begin{array}{c}\text { Increase } \\
(\%)\end{array}$ & $\begin{array}{c}\text { Before } \\
\text { processing }\end{array}$ & $\begin{array}{c}\text { After } \\
\text { processing }\end{array}$ & $\begin{array}{c}\text { Increase } \\
(\%)\end{array}$ \\
\hline FISH01 & 0.8892 & 0.8923 & 0.3486 & 0.9805 & 0.9913 & 1.1015 & 0.3295 & 0.3764 & 14.2337 \\
FISH02 & 0.8871 & 0.8895 & 0.2705 & 0.9798 & 0.9865 & 0.6838 & 0.7958 & 0.7999 & 0.5152 \\
FISH03 & 0.9684 & 0.9722 & 0.3924 & 0.8124 & 0.8217 & 1.1448 & 0.0195 & 0.0228 & 16.9231 \\
FISH04 & 0.8215 & 0.8324 & 1.3268 & 0.8577 & 0.8611 & 0.3964 & 0.3282 & 0.3560 & 8.4704 \\
FISH05 & 0.8417 & 0.8502 & 1.0099 & 0.8724 & 0.8841 & 1.3411 & 0.3534 & 0.3618 & 2.3769 \\
\hline
\end{tabular}

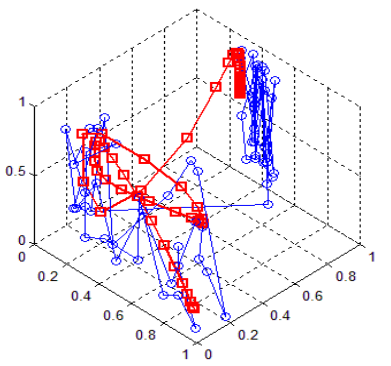

Left view $(45,45)$

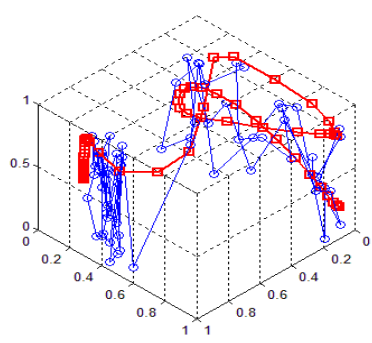

Right view (-45, -45)

Figure 6. Measured and fitted migration trajectories of Fish 01 after normalization

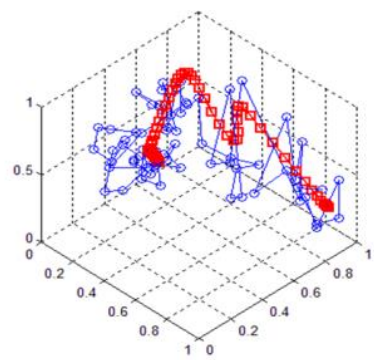

Left view $(45,45)$

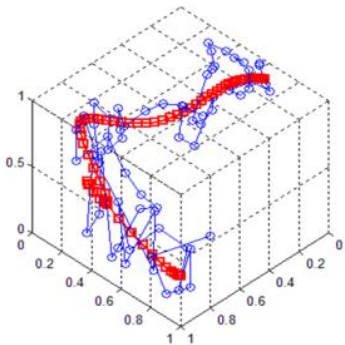

Right view $(-45,-45)$

Figure 7. Measured and fitted migration trajectories of Fish 02 after normalization

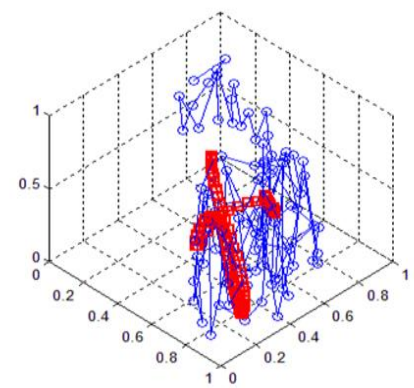

Left view $(45,45)$

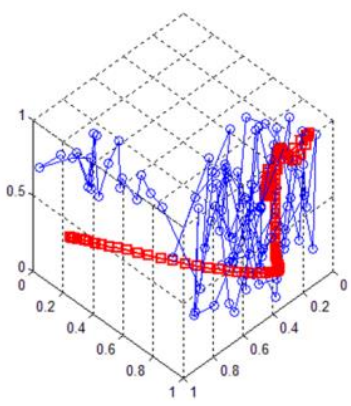

Right view (-45, -45)

Figure 8. Measured and fitted migration trajectories of Fish 03 after normalization 


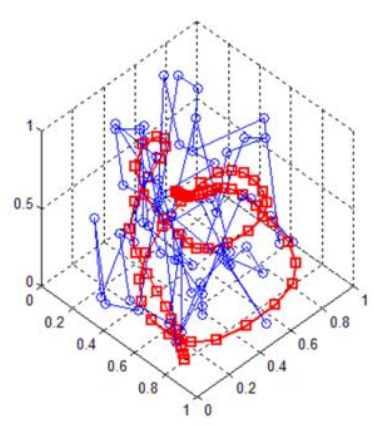

Left view $(45,45)$

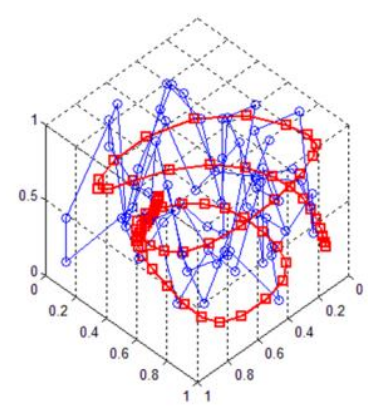

Right view $(-45,-45)$

Figure 9. Measured and fitted migration trajectories of Fish 04 after normalization

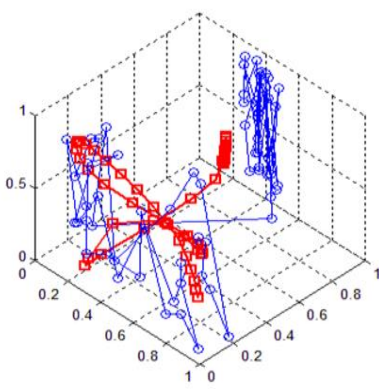

Left view $(45,45)$

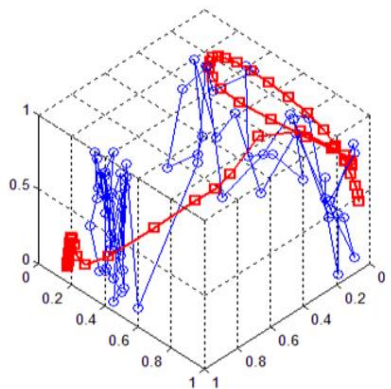

Right view $(-45,-45)$

Figure 10. Measured and fitted migration trajectories of Fish 05 after normalization

According to the fitted data, the correlation coefficients in $\mathrm{X}$ and $\mathrm{Y}$ directions were greater than 0.81 . Fish 03 boasted a good fitting performance in the $\mathrm{X}$ direction, and Fish 01 and 02 had correlation coefficients above 0.98 in the Y direction. These means the BPNN algorithm has a good fitting effect on the planar migration trajectories of the fish.

In the $\mathrm{Z}$ direction, the correlation coefficients of Fish 01,04 and 05 all fell in 0.32 0.37, while those of Fish 02 and 03 fell out of the range (the correlation coefficient of Fish 03 was as low as 0.01-0.02). Hence, the BPNN algorithm fails to achieve a desirable fitting result concerning the migration trajectories in the $\mathrm{Z}$ direction. $\mathrm{A}$ possible reason is that the $\mathrm{Z}$ values are the absolute elevations of the migrating fish, which cannot reflect the distance to the river bottom. The vertical distance between fish and river bottom is essential to the accurate evaluation of migration trajectories, in addition to the spatial distance between fish and water.

The normalization greatly enhanced the fitting effect of migration trajectories. The correlation coefficients of Fish 01-05 were improved across the board after the 3D images (Fig. 6-10) were considered. Specifically, the correlation coefficients in the X direction increased by $0.27-1.33 \%$ and those in the $\mathrm{Y}$ direction by $0.40-1.34 \%$. The greatest increase belongs to Fish 04 in the $\mathrm{x}$ direction $(1.33 \%$ from 0.82 to 0.83$)$ and Fish 05 in the y direction ( $1.34 \%$ from 0.87 to 0.88 ). In the $\mathrm{Z}$ direction, the fitting effect of each fish was enhanced obviously except Fish 02. After normalization, the correlation coefficients of Fish 01, 03, 04 and 05 all grew by over 2.30\%. Particularly, the correlation coefficient of Fish 03 increased by $16.92 \%$ in the $\mathrm{Z}$ direction. 


\section{Effects of water temperature and dissolved oxygen content on fish behaviours}

The growth, metabolism and cranial nerve movement of fish are closely related to the temperature and dissolved oxygen content at different water depths. Here, the behaviours of Fish 01-05 at different water depths were monitored (Table 5) and analysed in April (spring) and August (summer). The analysis shows that the temperature and dissolved oxygen content affected the fish's favourite water depth.

In spring, the average water temperature is $20.97{ }^{\circ} \mathrm{C}$, the average dissolved oxygen concentration is $6.13 \mathrm{mg} / \mathrm{L}$. Neither the water temperature gradient nor the dissolved oxygen content changed significantly across different water depths. Hence, the time that the fish dwelled in each water depth remained basically unchanged (Fig. 11).
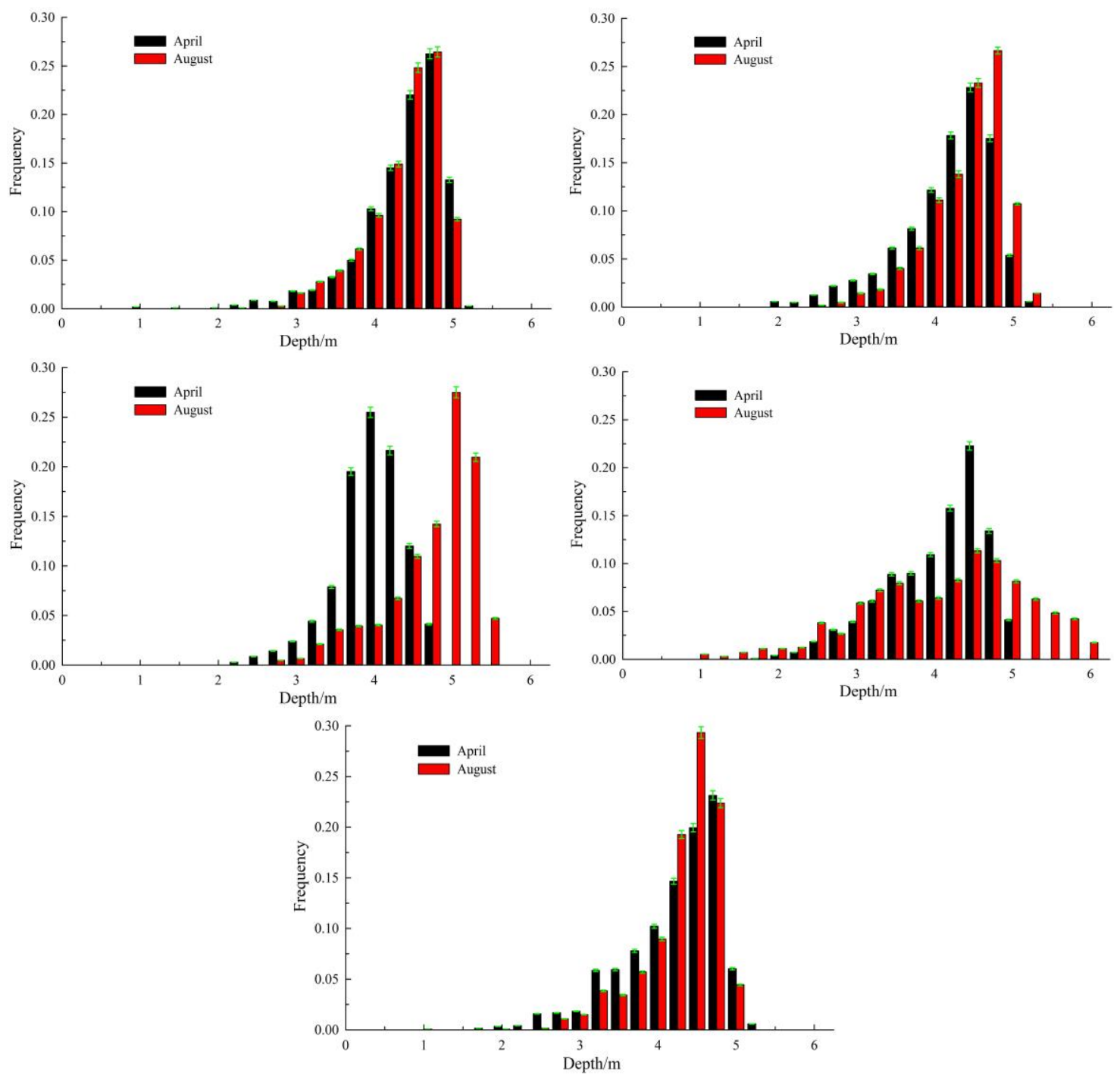

Figure 11. Distribution of fish residence time in different water layers

In summer, the average water temperature is $26.07{ }^{\circ} \mathrm{C}$, the water temperature was much higher than that in spring at all water depths. The surface temperature exceeded the preferred temperature of the fish, and the water temperature declined with the increase of the water depth. On the surface of the reservoir, the amount of phytoplankton and 
light intensity remained on a high level. Owing to the long illumination time, the dissolved oxygen content decayed slower in summer than in spring in different water depths. Thus, the fish descended to the depth with the most suitable water temperature and dissolved oxygen content. This is consistent with the research results of Kramer D L (1987).

The dissolved oxygen content plays a decisive role in the fish's selection of water depth (Breitburg, 1994). When the fish were swimming, they tended to choose the optimal depth based on their survival needs. The fish firstly selected the area with the proper content of dissolved oxygen, and then the area with the suitable water temperature. In spring, the fish preferred to stay in the water depth of $3.75-5.00 \mathrm{~m}$, where the temperature was $20 \pm 1.00{ }^{\circ} \mathrm{C}$ and dissolved oxygen content $5.00-6.00 \mathrm{mg} / \mathrm{L}$; in summer the fish preferred to stay in the water depth of $4.00-5.25 \mathrm{~m}$, where the temperature was $23.30-28.00{ }^{\circ} \mathrm{C}$ and the dissolved oxygen content $7.00-8.00 \mathrm{mg} / \mathrm{L}$.

Table 5. Comparison of water depths, water temperatures and dissolved oxygen contents of the fish in spring and summer

\begin{tabular}{l|c|c|c|c|c|c}
\hline \multirow{2}{*}{ Serial number } & \multicolumn{2}{|c|}{$\begin{array}{c}\text { The prefer depth of the } \\
\text { water }\end{array}$} & \multicolumn{2}{c|}{$\begin{array}{c}\text { Dissolved oxygen } \\
\text { concentration }\end{array}$} & \multicolumn{2}{c}{ Water temperature } \\
\cline { 2 - 7 } & Spring & Summer & Spring & Summer & Spring & Summer \\
\hline FISH01 & 4.75 & 4.5 & 5.859 & 7.617 & 21.974 & 23.972 \\
FISH02 & 4.5 & 4.75 & 6.271 & 7.460 & 20.682 & 25.937 \\
FISH03 & 4 & 5 & 6.493 & 7.270 & 19.997 & 27.901 \\
FISH04 & 4.5 & 4.5 & 6.071 & 7.617 & 20.372 & 26.592 \\
FISH05 & 4.75 & 4.5 & 5.959 & 7.617 & 21.862 & 25.937 \\
\hline
\end{tabular}

\section{Conclusions}

Based on the HTI acoustic tracking system and BPNN, this paper simulated and analysed the migration of the fish in the natural state, and the vertical distribution of fish was discussed at different temperatures and dissolved oxygen contents. The research findings can provide reference for the later experts to study fish behavior simulation.

The BPNN algorithm has a good fitting effect on the planar migration trajectories of the fish. However, it failed to achieve a desirable fitting result concerning the migration trajectories in the $\mathrm{Z}$ direction, because the $\mathrm{Z}$ values, the absolute elevations of the migrating fish, cannot reflect the distance to the river bottom. Fortunately, the fitting effect of migration trajectories were greatly enhanced by normalization.

The fish were distributed differently in spring and summer across the different water depths, under the influence of water temperature and dissolved oxygen content. Overall, the fish obeyed the normal distribution in the vertical direction, and selected water depth mainly based on dissolved oxygen content. When the fish were swimming, they tended to choose the optimal depth based on their survival needs. The fish firstly selected the area with the proper content of dissolved oxygen, and then the area with the suitable water temperature.

Acknowledgements. The work was supported by National Natural Science Foundation of China (NO.51569006 \& NO.51409050) , Guangxi Science and Technology Projects (NO.GUIKE 
AB17195074), Nanning Science Research and Technology Development Plan (NO.20183045-1) and Guangxi Key Laboratory of Water Engineering Materials and Structures.

\section{REFERENCES}

[1] Breitburg, D. L. (1994): Behavioral response of fish larvae to low dissolved oxygen concentrations in a stratified water column. - Marine Biology 120(4): 615-625.

[2] Cai, D., Li, R. (2012): Research on fish habitat based on acoustic fish tracking system. Journal of Convergence Information Technology 7(23): 195-201.

[3] Clark, R. D., Christensen, J. D., Caldwell, P. A., Matthews, G. A., Minello, T. J. (2004): A habitat-use model to determine essential fish habitat for juvenile brown shrimp (Farfantepenaeus aztecus) in Galveston Bay, Texas. - Fishery Bulletin 102(2): 264-77.

[4] Cruz-Font, L., Shuter, B. J., Blanchfield, P. J. (2012): Tracking lake trout habitat use using a new telemetry approach. - American Fisheries Society 1 Meeting 2012.

[5] Guo, W. X., Wang, H., Xu, J., Xia, Z. (2011): Effects of Three Gorges reservoir on the downstream eco-hydrological regimes during the spawning of important fishes. - Journal of Hydroelectricity 30(3): 22-26.

[6] Haim, A., Portnov, B. A. (2013): Effects of Light Pollution on Animal Daily Rhythms and Seasonality: Ecological Consequences. - Light Pollution as a New Risk Factor for Human Breast and Prostate Cancers. - Springer Netherlands, Dordrecht, pp. 71-75.

[7] Han, J. C., Liu, G. Y., Mei, P. S., Huang, Y. P., Liu, D. F., Chen, Q. W. (2010): Effects of temperature on the hematological indices and digestive enzyme activities of Crucian carp (Carassius auratus). - Journal of Hydroecology 3(1): 87-92.

[8] He, L. Z., Feng, M. H., Wang, L. Y. (2018): Analysis on stability of Fengting River dam slope based on three-dimensional finite element. - Water Conservancy Construction and Management (6): 20-24.

[9] Hecht Nielsen, R. (1988): Theory of the backpropagation neural network. - Neural Networks 1(1): 445-445.

[10] Jr, A. W. K, Matarese, A. C. (1994): Status of early life history descriptions of marine teleosts. - Text 92(4): 725-36.

[11] Kramer, D. L. (1987): Dissolved oxygen and fish behavior. - Environmental Biology of Fishes 18(2): 81-92.

[12] Monk, J., Ierodiaconou, D., Bellgrove, A., Harvey, E., Laurenson, L. (2011): Remotely sensed hydroacoustics and observation data for predicting fish habitat suitability. Continental Shelf Research 31(2): S17-S27.

[13] Mouton, A. M., Schneider, M., Depestele, J., Goethals, P. L. M., Pauw, N. D. (2007): Fish habitat modelling as a tool for river management. - Ecological Engineering 29(3): 305-15.

[14] Macbeth, C., Dai, H. (1997): Effects of learning parameters on learning procedure and performance of a BPNN. - Neural Networks the Official Journal of the International Neural Network Society 10(8): 1505.

[15] Pepin, P., Miller, T. J. (1993): Potential use and abuse of general empirical models of early life history processes in fish. - Canadian Journal of Fisheries \& Aquatic Sciences 50(6): 1343-45.

[16] Popper, A. N., Carlson, T. J. (1998): Application of sound and other stimuli to control fish behavior. - Transactions of the American Fisheries Society 127(5): 673-07.

[17] Riding, T. A. C., Dennis, T. E., Stewart, C. L., Walker, M. M., Montgomery, J. C. (2009): Tracking fish using 'buoy-based' GPS telemetry. - Marine Ecology Progress 377: 25562.

[18] Santana-Garcon, J., Newman, S. J., Harvey, E. S. (2014): Development and validation of a mid-water baited stereo-video technique for investigating pelagic fish assemblages. Journal of Experimental Marine Biology \& Ecology 452(1): 82-90. 
[19] Tan, D., Wang, J., Dan, S. (2004): The ratio of flesh to body and analysis on nutritive composition of muscle in Ancherythroculter nigrocauda. - Acta Hydrobiologica Sinica 28(3): 240-46.

[20] Valavanis, V. D., Pierce, G. J., Zuur, A. F., Palialexis, A., Saveliev, A., Katara, I., Wang, J. (2008): Modelling of essential fish habitat based on remote sensing, spatial analysis and GIS. - Hydrobiologia 612(1): 5-20.

[21] Wang, Y. R., Li, J., Li, K. F., Rui, J. L. (2007): Hydraulic parameters for the habitat demand of the water-reducing river in hydropower stations. - Journal of Water Conservancy 38(1): 107-11.

[22] Zhang, H., Wei, Q., Yang, G. (2008): Development trend and fishery application of echo sounder. - Water Conservancy and Fishery 28(1): 9-13.

[23] Zhang, Z. R., Xie, R. S., Xiao, L. Y., Wen, S. P. (1987): Effects of magnetic field and magnetic field on the growth of tilapia. - Journal of Tropical Ocean 1: 93-95. 